\title{
Educação em saúde no segmento adolescente sob a perspectiva das metodologias ativas de ensino-aprendizagem
}

\author{
Maria Inês Miranda Pacheco Borges*; Liliane Parreira Tannús Gontijo**; Marisa Aparecida Elias***; \\ Daniella Aparecida de Sousa Alves****; Eduarda Franco Rocha Gonçalves****; Isabel Cristiane de \\ Noronha****; Thiago Artur de Morais****
}

* Mestranda, Programa de Pós-Graduação, Mestrado Profissional em Saúde Ambiental e Saúde do Trabalhador, Universidade Federal de Uberlândia

** Professora Doutora Titular, área de Odontologia Preventiva e Social, Faculdade de Odontologia, Universidade Federal de Uberlândia

*** Professora Doutora Titular, Escola Técnica de Saúde, Universidade Federal de Uberlândia

**** Residente, Área de Concentração em Saúde Coletiva, Programa de Residência em Área Profissional da Saúde, Faculdade de Medicina, Universidade Federal de Uberlândia

Recebido em 24/06/2018. Aprovado em 11/09/2019.

\begin{abstract}
RESUMO
Trata-se de um estudo sobre prática da educação em saúde, com ênfase no autocuidado bucal e fundamentado nas Metodologias Ativas de Ensino-Aprendizagem (MAEA). As metodologias ativas possuem, dentre suas características, o deslocamento do protagonismo do educador para o educando, incentivando a sua inserção como principal responsável pela sua aprendizagem. Objetivou interagir, debater e promover a saúde e o autocuidado, com destaque na saúde bucal, de acordo com a realidade do grupo de adolescentes no contexto do Sistema Único de Saúde. O estudo foi desenvolvido por meio de duas oficinas, totalizando a participação de 40 adolescentes, em dias distintos e sequenciados. Centrou-se na reflexão do cotidiano, nos interesses, necessidades e nos contextos social e cultural dos adolescentes, buscando estimular um processo de desconstrução/construção de conhecimentos, propiciando a busca de novos e diferentes saberes. A experiência da prática educativa relatada recebeu avaliação positiva na percepção de seus educandos, bem como facilitou o diálogo e a interação entre os mediadores e adolescentes. Verificou-se a participação intensa dos adolescentes durante as oficinas e a reflexão crítica sobre o cuidado em saúde, ligada aos problemas da vida. A prática educativa promoveu a construção de possibilidades compartilhadas ao lidar com adversidades cotidianas e conflitos familiares, pois revelouse exitosa e repleta de potencialidades crítico-reflexivas na tomada de decisão em saúde, segundo a visão dos adolescentes.
\end{abstract}

Descritores: Adolescentes. Educação em Saúde. Aprendizagem. 


\section{INTRODUÇÃO}

A adolescência é um período crítico da vida, no qual ocorre a afirmação da personalidade e da individualidade, com vivências de descobertas significativas ${ }^{1}$. É, também, uma fase dinâmica, complexa e merece especial atenção, visto que é nesta etapa da vida que ocorre maior exposição às situações de risco, com predisposição aos agravos. Dessa forma, é necessário que as ações dirigidas aos adolescentes estimulem o seu autocuidado e o seu potencial criativo e resolutivo ${ }^{2}$.

Bub et al. ${ }^{3}$ (2006) defendem a vinculação das noções de autocuidado e de cuidado de si mesmo, bem como suas influências no campo da saúde. Nesse sentido, o autocuidado é vinculado à saúde humana, sendo que suas ações constituem a prática de atividades que os indivíduos desempenham de forma deliberada em seu próprio benefício com o propósito de manter a vida, a saúde e o bem-estar. Por outro lado, o cuidado de si mesmo é uma atitude ligada ao exercício da política, a certo modo de encarar as coisas, de estar no mundo, de relacionar-se com o outro e consigo mesmo; de agir de si para consigo, de modificar-se, purificar-se, se transformar, e transfigurar-se.

Diante desse prisma, as ações supracitadas do autocuidado são voluntárias e intencionais, envolvem a tomada de decisões, e têm o propósito de contribuir para a integridade estrutural, o funcionamento e o desenvolvimento humano. Elas são afetadas por fatores básicos tais como idade, sexo, estado de desenvolvimento e de saúde, orientação sociocultural, fatores do sistema de atendimento à saúde - modalidades de diagnóstico e de tratamento, fatores familiares e padrões da vida $^{3}$.

Habitualmente, os adultos cuidam-se voluntariamente. Os bebês, as crianças, os idosos, os enfermos e os deficientes necessitam de cuidado ou assistência completa nas atividades de autocuidado ${ }^{4}$. Por sua vez, os adolescentes mantem-se no limbo, ora se cuidam voluntariamente, ora precisam de supervisão e comando para as atividades de autocuidado, como por exemplo, para realização de sua higienização bucal.

Segundo dados do Projeto SB Minas Gerais 2012, pesquisa das condições de saúde bucal da população mineira, três em cada quatro adolescentes apresentam algum tipo de problema que exige intervenção odontológica ${ }^{5}$. Nesse contexto, torna-se fundamental reestruturar $\mathrm{e}$ ressignificar a atenção odontológica, no sentido de transcender o fomento aos aspectos clínicorestauradores, elevando o fortalecimento $\mathrm{e}$ qualificação da promoção da saúde, incluindo ações educativas significativas, democráticas e crítico-reflexivas, além da prevenção de doenças e agravos bucais, a fim de proporcionar a construção de práticas de saúde relevantes e socialmente aceitáveis.

Publicações nacionais e internacionais ${ }^{6,7}$ demostraram que adolescentes têm pouco conhecimento quanto à saúde bucal, inclusive sobre o que é necessário para sua obtenção. Estes estudos também retratam que a educação em saúde (ES) é fator importante para modificar comportamentos em saúde, principalmente se fundamentada em pedagogia participativa ${ }^{8-10}$. Verifica-se que a ES tem se pautado preferencialmente no método de transmissão de conhecimentos, sem considerar os interesses, necessidades e o contexto da população-alvo do cuidado ${ }^{11}$.

Torna-se necessário, portanto, repensar a ES numa abordagem crítico-reflexiva, de forma a possibilitar ao indivíduo uma atitude investigativa perante o mundo. Esta abordagem permite a imersão consciente dos educandos na experiência coletiva, carregada de afetos, valores, interesses sociais e políticos e conotações simbólicas ${ }^{8}$.

Assim, o presente estudo fundamentou-se nas abordagens educacionais construtivistas, com destaque para as Metodologias Ativas de Ensino- 
Aprendizagem (MAEA), as quais têm seu alicerce no princípio da autonomia, em que o aprendiz é capaz de autogerenciar ou autogovernar seu processo de formação, onde o indivíduo constrói a sua própria história ${ }^{12}$. A escola é um local privilegiado para as referidas práticas, onde os adolescentes têm a oportunidade de socializar e conviver com novas realidades e diferentes culturas $^{13}$.

Nessa perspectiva, o estudo elegeu adolescentes de uma escola pública para implementar uma prática educativa em saúde, com base nas MAEA, a fim de estimular o caráter crítico e reflexivo e possivelmente transformador. Objetivou-se interagir, debater e promover a saúde e o autocuidado, com ênfase na saúde bucal, de acordo com a realidade do grupo de adolescentes.

\section{METODOLOGIA}

$\mathrm{O}$ estudo foi desenvolvido durante quatro meses, em 2017, com adolescentes de uma escola municipal de ensino fundamental. Participaram 40 adolescentes do $9^{\circ}$ ano, turmas $\mathrm{A}$ e $\mathrm{B}$, de ambos os sexos, com idade variando entre 13 e 16 anos, divididos em dois grupos de 20. A abordagem e o recrutamento foram realizados pela direção da escola, com o apoio dos pesquisadores. Foram realizadas duas oficinas, aplicadas em dias consecutivos, com carga horária de quatro horas/dia, com base nas MAEA. As oficinas foram realizadas na própria escola, em horário extraclasse, garantindo ambiente de sigilo, sem qualquer prejuízo às suas atividades. Participaram também dessas oficinas 26 profissionais da equipe odontológica da Rede do Sistema Único de Saúde (SUS), na modalidade de observadores e executores.

A análise de conteúdo temática baseou-se na técnica de $\operatorname{Bardin}^{14}$, considerando as variáveis qualitativas subdivididas em quatro núcleos de sentido. $\mathrm{O}$ quadro 1 sintetiza as principais ações pedagógicas das duas oficinas.

Quadro 1. Ações pedagógicas das oficinas

\begin{tabular}{|l|l|}
\hline & \multicolumn{1}{c|}{ Ações Pedagógicas } \\
\hline & 1a etapa: Apresentação em modalidade dialogada dos participantes do estudo, mediante expressão de seus nomes e de \\
seu lazer. & \\
2a etapa: Vídeo: "7 Coisas que você deveria saber sobre os adolescentes"15 - ação pedagógica denominada faísca \\
educacional. Objetivou dar vazão às emoções, sentimentos e percepções dos adolescentes. Ação de compartilhamento, \\
a partir do recurso da tarjeta/pincel atômico, expressão de uma palavra ou pequena frase, sentimento, emoções e \\
percepções, estimuladas pelo vídeo.
\end{tabular}


O estudo foi aprovado pelo Comitê de Ética em Pesquisa sob número CAAE, 61266716.1.0000.5152. Após a concordância em participar da pesquisa, foi solicitado ao adolescente, a assinatura do Termo de Assentimento para o Menor e a autorização dos pais e/ou responsáveis para a referida participação, registrada mediante da assinatura do Termo de Consentimento Livre e Esclarecido (TCLE).

\section{RESULTADOS E DISCUSSÃO}

\section{Núcleo 1 - Como os participantes chegaram?}

Os estudantes foram recebidos pelos pesquisadores em um ambiente previamente preparado de modo a oferecer um espaço diferente da sala de aula tradicional. As cadeiras foram dispostas em círculo e os materiais que seriam utilizados estavam disponíveis na sala. Os pesquisadores se apresentaram visando a interação e o estabelecimento de um ambiente de confiança.

Observou-se receptividade e, logo ao primeiro contato, os adolescentes demonstraram espontaneidade, interesse e motivação para a presente proposta. Mostraram-se à vontade em relacionar os temas de interesse e conhecimento e mantiveram-se eufóricos quando surgiu o interesse pelos temas sexualidade e sexo oral, ratificando, novamente, despojamento, fluidez na abordagem do tema e não constrangimento frente à presença de profissionais externos à escola.

$\mathrm{Na}$ primeira oficina os adolescentes foram recepcionados com um lanche, tendo como intencionalidade educacional as boas-vindas ao espaço pedagógico, socialização e interação entre os participantes, educandos e educadores. Expressou-se como momento importante de acolhimento e descontração. Os adolescentes inicialmente se mostraram desconfiados, mas muito animados e eufóricos. $\mathrm{Na}$ introdução das primeiras conversas foi comum prevalecer a timidez, cochichos uns com os outros, receio em se expor, expressões gestuais representativas de embaraço e inibição, todavia, em pouco tempo observou-se a transposição para a interação, destemidez, extroversão e sociabilidade.

Coexistiu nas falas dos adolescentes suas expectativas e avaliação em julgar que ia ser um encontro como tantos outros.

"Eu achei que ia ser ruim, mas foi legal."

\section{(A13)}

"Eu também confesso que eu achei que ia ser chato, mas foi divertido." (A10)

$\mathrm{Na}$ plenária da $2^{\mathrm{a}}$ oficina, os questionamentos depositados nas urnas pelos adolescentes foram agrupados pelos pesquisadores em núcleos de sentido para proporcionar agilidade e contemplar o diálogo das indagações, dentre elas: (1) questões da vida, relações, encontros, família e sexualidade; (2) saúde geral e (3) saúde bucal.

Importante salientar que no tema saúde bucal os questionamentos trouxeram algumas demandas, entre elas: porque surgem e como cuidar/acabar com as aftas; causas e prevenção do câncer de boca; se sexo oral é aconselhável ou prejudica a saúde bucal; se os dentes amarelam/escurecem com o tempo, dependente da genética, do esmalte, de corantes da alimentação ou da higienização bucal; como clarear os dentes (no domicilio ou no consultório odontológico) e se esse processo os enfraquece; se problemas nasais e de digestão podem fazer a pessoa ter mau hálito; doenças transmitidas pelo beijo; horários certos para escovar os dentes; e o interesse/desejo de uso do aparelho ortodôntico. Verificou-se que os adolescentes têm suas indagações autênticas e legítimas e, em consequência, a educação em saúde, necessariamente, deveria sempre partir dos interesses, necessidades e conhecimento prévio do educando.

Os adolescentes estavam animados e curiosos, pois era o momento de tirar as dúvidas sobre vários temas elaborados a partir de seus interesses e proveitos. Alguns se mostraram 
tímidos e com receio de que pudessem ser identificados a partir de seus questionamentos. Contudo, à medida que perceberam a preservação do sigilo e anonimato dos autores das perguntas, notou-se, gradativamente, intensa participação concomitante à diminuição das inquietudes.

Alguns depoimentos significativos dos adolescentes, durante a discussão do mote da saúde bucal, são refletidos a seguir:

"Tenho muito medo de dentista, aquela maquininha, né." (A13)

"Eu acho que as crianças, tipo assim, tomam medo de dentista pelo fato do barulho e não pela dor, porque a gente não sente nada, é pelo barulho mesmo". (A2)

"Ter saúde bucal é, não ter bafo, ter dentes brancos, beijar sem bafo (risos) ... não ter doença da boca e nem beijar muitas pessoas porque causam sapinho (risos)". (A11)

"A gente sabe que uma gengiva não tá sadia quando ela tá bem vermelha." (A4) "As pessoas começam a usar aparelho a partir da adolescência. Muitas vezes as crianças olham aquilo lá e falam, nossa, pessoa madura já, adolescente. Então isso contava muito, chamava atenção, queria ser tratada como pessoa mais velha. Então isso que fazia a pessoa querer usar também”. (A1)

"A gente não foi acostumada a conversar sobre sexo oral. É constrangedor (risos)".

Todos os assuntos abordados foram tratados na oficina pelos pesquisadores com muita naturalidade, perspicácia, uso de evidências científicas e, principalmente, com amorosidade, zelo, cuidado e compromisso com a ciência e consciência da necessidade de discussão de mitos e tabus. Ora cerceado ao fórum íntimo, ora expandido a curiosidade sobre temas pouco debatidos e silenciados. Sempre cônscios do propósito de orientação básica e esclarecimentos para o autocuidado e o cuidado de si mesmo, no contexto da saúde conectada a vida, seja acerca da puberdade e sexualidade afloradas, em que se encontram, desde os questionamentos de fácil a difícil argumentações.

\section{Núcleo 2 - As potencialidades e transforma- ções durante as oficinas}

A ação educacional, com finalidade de apresentações na primeira oficina, proporcionou momentos de descontração e os adolescentes exprimiram despreocupação e serenidade, demostrando não constrangimento. Nessa dinâmica, os adolescentes caracterizaram sua concepção de lazer sob a perspectiva da associação com boas práticas de saúde, explicitados em manifestações do tipo:

"O que eu entendo de lazer, é um momento de descanso, que a gente pode fazer o que a gente quer e quando der vontade." (A2) "Algo que você sente prazer em fazer." (A4)

A intencionalidade educacional, de aproximação/conhecimento/interação ao mundo adolescente e promoção de associações entre "os momentos de lazer", com a necessária busca de equilíbrio e saúde, se cumpriu, visto que se observou envolvimento e diversão entre os adolescentes com a ação proposta.

No grupo participante pode-se identificar muitas habilidades artísticas no campo da música, dança e esportes como detectado nas falas:

"Eu gosto muito de desenhar, de cantar." (A9)

"Meu prazer é sair com amigos, ficar com a familia e praticar esportes." (A4)

Nessa oportunidade, os adolescentes foram convidados a compartilhar seus talentos na oficina subsequente.

Após a ação faísca educacional, os adolescentes compartilharam suas emoções, 
articulando o que os tocou mais fortemente e abriuse um diálogo sobre os assuntos de seus interesses. Dos temas abordados, o uso de drogas lícitas e ilícitas foi uma das questões mencionadas que gerou grande fascínio. O A7 expressou a questão do "não julgar":

"Tem que ter muito respeito, né por estas pessoas, porque não é à toa que ela tá ali usando droga, né. Às vezes o pai não ama, a mãe não ama. Tem muitas pessoas que falam, seu caráter é com quem você anda. Eu acho que não tem a nada a ver, eu fico muito em praça, já me ofereceram, mas eu nunca usei, porque eu não quero acabar com minha saúde, entendeu?" (A7)

Foram abordados também temas sobre namoros, relacionamentos, amizades e temas gerais como evitar espinhas e como prevenir infecções sexualmente transmissíveis - IST. Ocorreram vários momentos de discussões, nas quais os adolescentes mostraram maturidade $\mathrm{e}$ reflexão. São jovens com poder de crítica e questionadores como nas narrativas:

"Cada um tem seu jeito. A gente tem que saber dialogar, adaptar cada um em si."

"Às vezes as pessoas pra aprenderem, precisam passar por alguns processos de decepções, errar pra poder acertar." (A1)

$\mathrm{O}$ trabalho em grupo configurou-se em atividade educacional dinâmica e criativa, onde os adolescentes puderam compartilhar suas ideias. $\mathrm{O}$ conhecimento no coletivo foi construído e trabalhado entre adolescentes e mediadores. Desta forma, foi relevante o envolvimento dos adolescentes, cada um ao seu jeito, promovendo assim nova aproximação entre pesquisadores e sujeitos do estudo, fortalecendo a interação e apropriação da visão de mundo e realidade dos mesmos.

Ao final da oficina houve sensibilização e corresponsabilização entre adolescentes e pesquisadores na busca de temas de interesse, visando a dialogia no encontro seguinte.

Na plenária dos trabalhos em grupo notou-se que os adolescentes sistematizaram suas ideias com respostas objetivas e comprometidas com a abordagem em saúde ampla e integral. Deste modo, notou-se que eles compreendem saúde, por meio de suas exposições, a partir de "uma vida estável, tranquila e sem preocupações". Nesse momento, emergiu a polêmica do padrão de beleza imposto pela mídia (magreza, "fitinização", etc.). Um adolescente pronunciou: "Fora capitalismo", todavia o A1 já argumentou com um depoimento que levantou aplausos: "Querendo ou não a gente vive dele. É algo chamativo [...] nos proporciona mais vontades, mais prazeres, mais lazeres. $O$ capitalismo faz parte da população, a gente não precisa acabar com ele, mas precisa saber lidar com ele."

E, também, traz ideias mais otimistas como na fala do A5: "Ter saúde é sentir bem, se olhar no espelho e gostar do que vê." Surgiu também a questão da saúde mental por meio de preocupações em relação à depressão, ansiedade e estresse.

As temáticas do autocuidado, do cuidado de si mesmo, da autoestima e saúde, promoveram a reflexão sobre a importância do resgate do amor próprio e da valorização pessoal. Explicitaram gratidão pelo espaço educativo e pela atenção e respeito deferida aos mesmos, como nas falas:

"Foi ótimo! Amamos tia, amamos". (A5)

"Foi muito bom, com certeza quero que tenha mais trabalhos como esse. Estou aliviada agora, estou melhor comigo mesmo e minha saúde mental está renovada." (A10)

Ao possibilitar que os próprios adolescentes escolhessem os temas de maior interesse para início e processamento do diálogo criou-se um momento de escuta ampliada, pois relataram seus questionamentos, conflitos e inseguranças. A partir da pergunta “Por que nós existimos?", foi possível 
problematizar os propósitos da vida, as razões e o sentido de tudo.

"Se a gente tá aqui é porque tem algum propósito, melhorar o mundo de alguma forma. Então você não tem que pensar porque você existe você tem que pensar o que você vai fazer pra tornar este novo lugar melhor". (A5)

Os depoimentos dos adolescentes sobre saúde bucal mostraram um discurso convencional, versando sobre o conhecimento básico sobre hábitos de higienização e prevenção de doenças bucais. $\mathrm{O}$ momento mais provocador revelou-se na resposta à pergunta sobre "Como fazer sexo oral?" Traduziu-se em momento de euforia, contudo, os mediadores conduziram as discussões de forma tranquila, e observou-se que os adolescentes se sentiram à vontade para fazer comentários, como do tipo do A1: "Porque fazer sexo oral? Porque é legal." Outros já se sentiram constrangidos e questionaram: "Como alguém poderia ter feito uma pergunta dessas?" Após as orientações e esclarecimentos, abordados de forma natural e espontânea, os próprios adolescentes concluíram que "cada um tem que fazer aquilo que te faz bem e ao outro".

Surgiram também questões no campo do namoro, gravidez, a prevenção contra doenças sexualmente transmissíveis, "pílula do dia seguinte" e opção/condição sexual e gênero. Quanto ao uso da camisinha um adolescente questionou: "o que fazer quando ficar com um menino e ele não quer usar preservativo?" A14 se pronunciou: "A gente tem que saber quem faz bem pra gente, essa pessoa aí não faz bem não."

Nesses encontros, os adolescentes puderam expressar suas angústias sem críticas e julgamentos e revelaram ter sido um momento importante de escuta, conforme os relatos:

"Achei interessante! Abordamos diversos assuntos e tiramos dúvidas que talvez tínhamos vergonha de conversar com alguém." (A2)

"Foi muito prazeroso conversar com pessoas que nos entendem. Obrigado!" (A8)

"Achei muito bom. Eu aprendi muitas coisas boas e me aliviei um pouco, quero bis." (A15)

Os alunos se reuniram ao final e fizeram um agradecimento com entrega de ramalhete de flores para os pesquisadores com aplauso de todos. A15 agradeceu:

"Eu queria agradecer em nome da turma, a presença de vocês, por ensinar a gente mais do que a gente já sabe, né. Por ter tocado no coração da gente, ter feito a gente ser mais, entendeu? Essas flores tão representando todas vocês, com amor $e$ carinho de todos nós." (A15)

$\mathrm{O}$ oferecimento de lanches, ao final de cada encontro, favoreceu a socialização da comunidade de aprendizagem na construção e na consolidação da interação e potencialização de vínculos no grupo, conforme observado nas falas:

"Quando a professora falou que ia ter comida, eu animei." (A13)

"Queria ter mais encontros, não é por causa do lanche, mas por causa que foi bom mesmo." (A7)

\section{Núcleo 3 - As dificuldades, fragilidades e divergências.}

Já na primeira oficina vieram à tona "segredos" e experiências íntimas de alguns adolescentes, trazendo a reflexão. $\mathrm{O}$ depoimento de uma adolescente foi muito marcante, pois ela logo no início se abriu, sem demonstrar constrangimento.

"O que eu gosto é de dançar, mas meu pai não deixa porque diz que isso é coisa pra puta. [...] E também não gosto de ficar com minha família, porque eles nunca me entendem. Eu tinha um 
namorado e eu descobri que fazia coisas erradas e quando terminei com ele ficou me jurando de morte [...] até matarem ele e eu achei muito bom. A minha mãe quer me obrigar a ser evangélica, mas eu acho que isso não é comigo. Eu também tenho um padrasto e eu sempre odiei [...]" (A13)

O espaço educativo, disponível à escuta e com base no diálogo, estimulou os depoimentos de vida repletos de conflitos familiares, de gerações e de relações presentes na vida dos adolescentes. Constatou-se, nessa experiência exitosa, o alcance de um ambiente educativo acolhedor, a promoção da confiança para compartilhamentos de angústias, tanto com seus pares, quanto junto aos mediadores de aprendizagem.

Apesar dos assuntos aparentemente serem distantes da temática odontológica é importante destacar que saúde não deve ser pensada fora de um contexto amplo que envolve mente e corpo. Ao deixar o tema livre, foi possível permitir que os jovens abordassem as questões que eram mais presentes e de inquietude a eles naquele momento. A temática específica pôde ser incluída durante os debates e assim oportunizouse se pensar numa educação em saúde de modo mais amplo, sob a concepção de aprendizagem significativa.

Alguns relatos dos adolescentes foram contundentes e reveladores:

"Muitas vezes os adultos não entendem que na nossa mente é tudo uma bagunça, de vez em quando a gente fica triste, estressado, que é uma bagunça." (A9) "É... às vezes na adolescência a gente vai muito pela emoção e não pela razão." (A1)

"Quando tá muito bagunçada a minha cabeça, muito conflito, eu durmo. Eu durmo pra ajeitar, e aí ajeita, quando amanhece no outro dia, eu to melhor" (A7)

Os conflitos familiares apareceram muito fortes, e as relações familiares com peso decisivo e significativo na vida e saúde dos adolescentes. Eles trouxeram muitas angústias e questionamentos como nos depoimentos:

"Eu acho que os pais têm que entender que a nossa felicidade é diferente da deles. E a maioria das minhas brigas com minha mãe é porque ela quer que eu faça uma coisa que eu não quero fazer. É o que ela sonhou pra mim, mas não é o meu sonho." (A9)

"Dói muito o desprezo da minha mãe biológica. Melhor ter uma mãe grossa, do que te desprezar, como cê não fosse ninguém, da família dela. Então eu prefiro encarar uma briga do que tá passando pelo que tô passando." (A6)

A temática "relações familiares" foi recorrente e ocorreu a partir da indagação de um adolescente sobre: "O que fazer quando a sua família não te aceita?" As reflexões partiram do pressuposto de que a primeira ação nesse caso é se conhecer e, constantemente, realizar reflexão crítica sobre a vida e promover espaços de diálogo.

$\mathrm{Na}$ plenária do trabalho em grupo abordaram questões de alimentação saudável, exercícios físicos, higiene e autoestima. Alguns participantes sinalizaram autoestima baixa. Alguns relataram não gostar de se olhar no espelho. $\mathrm{O}$ câncer foi uma das doenças citadas de maior preocupação para esse grupo, considerando seu caráter incurável e o medo de morrer. Reconhecem a Acquired Immunodeficiency Syndrome - AIDS, a diabetes e a depressão como doenças prevalentes do século XXI e durante o processo mencionaram sobre outras doenças comuns em seu convívio, dentre elas dengue, malária, Human Papiloma 
Virus - HPV e Zika Vírus.

A compreensão da existência de doenças curáveis e, por outro lado, as controláveis, no processo de ensino-aprendizagem do encontro, resultou no aprofundamento de uma questão ampla e contemporânea, fruto da crítica do processo saúde-doença-cuidado, objeto das MAEA nessa prática educativa.

Questões intimas foram abordadas espontaneamente pelos alunos como a falta de amor da mãe. Um adolescente concedeu seu depoimento, mostrando que na sua percepção, apesar de não ter esse amor materno, ele considera que lida bem com esse tipo de sentimento.

"Eu nunca tive amor da minha mãe e nem do meu pai, sabe. Eu sou super alegre, $e$ tal, quem me vê feliz desse jeito, nunca pensou que eu enfrento por estas coisas. Eu sou um cara bem alegre e nunca precisei do amor da minha mãe e nem do meu pai pra me fazer feliz. Eu fui procurar amor em outras coisas que me faziam feliz. Meus amigos também me fazem super feliz." (A7)

Os facilitadores buscaram acolher e promover a reflexão sobre as dificuldades deles com os pais, porém esses assuntos ressaltam que um maior conhecimento sobre questões psicológicas é importante para os profissionais que se dispuserem a desenvolver saúde.

Houve discussões calorosas das questões: "Por que as pessoas são tão falsas? E por que temos inimigos?" Os adolescentes demonstraram, com espontaneidade, conflitos e decepções nas amizades, justificando com argumentos próprios, delegados aos sentimentos da inveja, falta de amor próprio e pessoas com comportamento dissimulado. A12 tentou definir um conceito do que é ser falso: "Eu acho que é porque tem pessoas que tem inveja do que cê tem, e ao invés de cuidar da vida dela, vai cuidar da gente." Concluíram que o importante é "refletir antes de fazer as coisas".

Ficou clara a necessidade do diálogo, da escuta sem julgamento, ditando normas preestabelecidas, mas construindo as possibilidades de forma conjunta e dialogada. Ficou explícita a dificuldade em enfrentar essa fase. A6 relata: "É uma fase, ninguém me ama, ninguém me quer." A 14 mostra a sua angústia: "Não é muito fácil de passar esta fase, e não tá passando."

A grande demanda de questionamentos dos adolescentes não permitiu contemplar a discussão plena de todos os temas abordados. Porém, os encontros primaram pelo desenvolvimento de vínculos de confiança entre pesquisadores e adolescentes e entre eles mesmos, expondo-se espontaneamente, revelando seus medos, suas dúvidas e se abrindo ao diálogo, proporcionando um rico espaço de discussão e reflexão-crítica.

\section{Núcleo 4 - Avaliação: os impactos na percepção do processo ensino-aprendizagem.}

A oficina 1 foi considerada pelos adolescentes momento educativo de construção, interação em que puderam discutir assuntos da sua realidade e que trouxe reflexões, aflorando muitos sentimentos.

"Então estas reuniões assim, pode não parecer, é só uma reunião, tal, mas não, elas vão servir para o nosso futuro. Então isso vai ajudar muito a gente, se um dia a gente for pai, eu vou guardar isso sempre na lembrança, pra eu poder respeitar meu filho." (A2)

O formato das oficinas proporcionou aos adolescentes momentos de reflexão-crítica, aprendizagem e o reconhecimento da necessidade de mais encontros com as características dos elementos das MAEA, como mostra a pergunta do A9: "Podemos ter mais encontros como esses?" 
Manifestaram satisfação, oportunidade para o diálogo, liberdade ao conversar sobre qualquer assunto e espaço favorável aos desabafos. A5 expressou: "No meu caso, eu sou uma pessoa, tipo, junto muito as coisas, e às vezes desabafar é muito bom, se a gente não desabafa a gente acaba surtando."

Após análise e discussão da equipe executora, referente às avaliações advindas dos adolescentes, verificou-se que de forma geral a prática educativa impactou positivamente os adolescentes. Nesses registros, as expressões "incrível e sensacional", "maravilhoso", "ótimo e extraordinário", foram bem recorrentes e vistas de forma muito positiva pela equipe de mediadores.

Falas mostraram que a oportunidade de participação neste projeto, marcou de alguma forma as suas vidas e aprendizados, conforme A8: "Foi incrivel! São aprendizados que levarei para sempre." A15 comenta:

"Bom gostei de ser acolhida muito bem por todos. E o projeto foi o melhor que já participei. Quero agradecer a todos que me deram força e que me ajudaram a me reerguer. Vocês são as melhores mães e pessoas do mundo. Te amamos!!” (A15)

Em relação ao conteúdo abordado nas oficinas, foi possível perceber que o grupo de adolescentes se sentiu majoritariamente contemplado, porque expressões como "tiramos dúvidas que talvez tínhamos vergonha de conversar", "aprendi muitas coisas", "aprendizado que levarei para sempre", apareceram repetidas vezes.

Um dos princípios das metodologias ativas é a construção coletiva do conhecimento. Muitos registros, dentre eles: "tivemos a oportunidade de aprender”, "aprendi muitas coisas que não sabia sobre saúde", "tiramos dúvidas", "pudemos desabafar e conversar entre outras coisas", permitiram a percepção desse conhecimento.

A partir do que os adolescentes escreveram, como por exemplo: "foi prazeroso conversar com pessoas que nos entendem", "me aliviei um pouco", "quero bis", "gostei de ser acolhida por todos", foi possível perceber que a metodologia utilizada resultou em ambiente apropriado ao ensino-aprendizado ativo.

Após os agradecimentos, os adolescentes vieram espontaneamente nos abraçar demostrando afetividade e que o espaço pedagógico foi significativo para os mesmos. Ao final da oficina 2, houve um momento de confraternização revelando suas músicas, desenhos e danças. Os adolescentes estavam sensibilizados e motivados a realizar essa atividade. Salienta-se que esse momento artístico e lúdico, ao final da oficina, atingiu seus objetivos de socialização, construção de conhecimentos e aproximação entre adolescentes e equipe executora. Favoreceu também a criatividade e foi um dos pontos fortes da prática avaliativa das oficinas.

Foi contundente a construção do processo de ensino-aprendizagem a partir dos conhecimentos prévios e vivências dos adolescentes em seu contexto real de vida e conflitos efervescentes no período de transição entre a infância e a vida adulta. Constituiu-se essencial partir do interesse deles, despertando curiosidade e envolvimento, tornandoos protagonistas desse percurso educacional.

$\mathrm{Na}$ metodologia participativa, os adolescentes selecionam os temas a serem abordados/debatidos, possibilitando um espaço dinâmico de trocas e descobertas. Uma das vantagens é minimizar a timidez dos jovens, contribuindo para um melhor aprendizado ${ }^{16}$.

A maneira como a sala (espaço pedagógico) foi disposta, em forma de círculo, bem como as dinâmicas grupais, facilitaram a concepção dialógica e interacionista, promovendo interlocuções com as situações de vidas dos adolescentes. $\mathrm{O}$ círculo proporciona uma vivência participativa, facilitando a reflexão-ação ${ }^{17}$. As dinâmicas grupais permitem que os participantes 
reflitam e possibilitam a busca de soluções para seus problemas, em um ambiente lúdico ${ }^{18}$.

A interação dos adolescentes com os mediadores favoreceu o processo ensinoaprendizagem, proporcionando momentos de trocas e vivências. A mediação é um aspecto fundamental para a aprendizagem, pois a construção do conhecimento ocorre a partir do processo de interação entre as pessoas ${ }^{19}$.

A questão dos conflitos familiares foi um dos pontos fortes das oficinas, mostrando adolescentes vulneráveis que necessitam de escuta e acolhimento. Observou-se também fragilidades nas relações de amizades. Enquanto para alguns é um período de turbulências, outros passam por esta fase sem manifestarem maiores problemas e dificuldades. Na adolescência também surgem as verdadeiras relações de amizade e uma maior capacidade em expressar valores ${ }^{20}$.

Diante das angústias e conflitos, os adolescentes se sentiram acolhidos, encontraram espaço para o diálogo e confiança em compartilhar suas dificuldades. Importante a postura acolhedora, o olhar cuidadoso e a escuta ampliada do facilitador de aprendizagem, com base na formação de vínculos e relações de confiança ${ }^{21}$.

A experiência com este grupo de adolescentes, por meio das MAEA, estimulou e motivou o interesse desses jovens e trouxe novos significados na visão de saúde-doença saúde-lazer; saúde e bem-estar familiar. Os mecanismos do aprender são mais eficientes quando o estudante consegue agregar e incorporar significados aos novos conteúdos, utilizando de seus conhecimentos prévios, trazendo uma aprendizagem significativa ${ }^{22}$.

$\mathrm{O}$ estudo permitiu a reflexão de conhecimentos sobre o processo saúde-doençacuidado a partir da realidade dos adolescentes. Neste contexto da ES, validou-se a importância da utilização das MAEA junto ao segmento adolescente. Proporcionou a reflexão compartilhada responsável e estimulou a participação dialogada e ativa conduzindo a troca de saberes e empoderamento dos sujeitos. Somente por meio de uma prática reflexiva e crítica pode-se promover o diálogo e a autonomia para o enfrentamento de resistências e de conflitos ${ }^{23}$.

A experiência posta representou a combinação estratégica entre ações educativas proativas, inventivas, alegres e respeitosas, mediada pelo ensino-aprendizagem singular, amoroso, cuidadoso, acolhedor e compromissado com o desenvolvimento consistente do ser humano, representando práticas promissoras de educação em saúde.

\section{CONCLUSÃO}

Conclui-se que a prática educativa promoveu a construção de possibilidades compartilhadas ao lidar com adversidades cotidianas e conflitos familiares, pois revelou-se exitosa e repleta de potencialidades crítico-reflexivas na tomada de decisão em saúde, segundo a visão dos adolescentes.

\section{ABSTRACT \\ Health education in the adolescent segment from the perspective of active teaching-learning methodologies}

This study addressed the practice of health education, with emphasis on oral self-care and based on Active Teaching-Learning Methodologies (ATLM). The active methodologies present, among their characteristics, displacement of protagonism from the educator to the student, encouraging their insertion as the main responsible for their learning. It aimed to interact, discuss and promote health and self-care, with emphasis on oral health, according to the reality of the group of adolescents within the context of the Brazilian Unified Health System. The study included two workshops, involving participation of 40 adolescents, on different and sequenced days. It focused on the reflection of daily life, interests, 
needs and the social and cultural contexts of adolescents, aiming to stimulate a process of deconstruction/construction of knowledge, providing the search for new and different knowledge. The reported experience of educational practice was positively evaluated in the perception of students, and facilitated the dialogue and interaction between mediators and adolescents. There was intense participation of adolescents during the workshops and critical reflection on healthcare, related to life problems. The educational practice promoted the construction of shared possibilities in dealing with daily adversities and family conflicts, as it proved to be successful and full of criticalreflexive potentialities in health decisionmaking, according to adolescents' standpoint.

Descriptors: Adolescents. Health Education. Learning.

\section{REFERÊNCIAS}

1. Baldoino LS, Silva SMN, Ribeiro AMN, Ribeiro EKC. Educação em saúde para adolescentes no contexto escolar: um relato de experiência. Rev Enferm UFPE on line. 2018:12(4):1161-7.

2. Ramos FRS, Heidemann ITSB, Cardoso J. Saúde do Adolescente. Florianópolis: Universidade Federal de Santa Catarina, 2010. [Acesso em 04 de jun. 2018]. Disponível em: file:///C:/Users/dgp/Down loads/MOD\%2010\%20(1).pdf

3. Bub MBC, Medrano C, Silva CD, Wink S, Liss PE, Santos EKA. A noção de cuidado de si mesmo e o conceito de autocuidado na enfermagem. Texto Contexto Enferm. 2006:15 (Esp): 152-7.

4. Orem DE. Nursing: concepts of practice. 4th ed. St Louis (USA): Mosby Year Book Inc.; 1991.

5. Pinto RS, Leal DL, Santos JS, Roncalli AG. Projeto SB Minas Gerais 2012: Pesquisa das condições de saúde bucal da população mineira - métodos e resultados principais.
Arq Odontol. 2018: 54:(e14):1-11.

6. Thomson WM, Locker D, Poulton R. Incidence of dental anxiety in young adults in relation to dental treatment experience. Comm Dent Oral Epidemiol. 2000: 28(4):289-94.

7. Figueiredo MC, Garcia M, Barone DAC, Oliveira R, Lurmmerz G. Gamificação em saúde bucal: experiência com escolares de zona rural. Rev ABENO. 2015: 15(3):98108.

8. Alves MNT, Marx M, Bezerra MMM, Landim JMM. Metodologias pedagógicas ativas na educação em saúde. Id on Line Rev Psic. 2017:10(33) supl 2:339-46.

9. Santos JS, Andrade RD, Mello DF, Maia MAC. Educação em saúde na adolescência: contribuições da Estratégia Saúde da Família. Rev Soc Bras Enferm Ped. 2014:14(1): 20-6.

10. Simon E, Jezine E, Vasconcelos EM, Ribeiro KSQS. Metodologias ativas de ensinoaprendizagem e educação popular: encontros e desencontros no contexto da formação dos profissionais de saúde. Interface Comunic Saúde Educ. 2014:18(supl 2):1355-64.

11. Figueiredo MFS, Neto JFR, Leite MTS. Modelos aplicados às atividades de educação em saúde. Rev Bras Enferm. 2010;63 (1):117-21.

12. Freire P. Pedagogia da autonomia: saberes necessários à prática educativa. $33^{\mathrm{a}}$ ed. São Paulo: Paz e Terra; 2006.

13. Dantas TM, Machado MFAS, Marinho MNABS, Silva BT, Alencar DL, Barbosa LA. Educação em Saúde como Ferramenta na Saúde Sexual do Adolescente. Cad Cult Ciência. 2010; 1(2):12-22.

14. Bardin L. Análise de Conteúdo. $4^{\mathrm{a}}$ ed. Lisboa: Edições 70; 2011.

15. Freitas, R. 7 Coisas que você deveria Saber sobre os Adolescentes. [Acesso em 26 de jan. 2018]. Disponível em: https://www.youtube. 
com/watch?v=yEGiBq-tzAY

16. Fonseca AD, Gomes VLO, Teixeira KC. Percepção de adolescentes sobre uma ação educativa em orientação sexual realizada por acadêmicos (as) de enfermagem. Esc Anna Nery Rev Enferm. 2010;14(2):330-7.

17. Monteiro EMLM, Vieira NFC. Educação em Saúde a partir de Círculos de Cultura. Rev Bras Enferm. 2010;63(3):397-403.

18. Ferreira MA. A educação em saúde na adolescência: grupos de discussão como estratégia de pesquisa e cuidado-educação. Texto Contexto Enferm. 2006;15(2):205-11.

19. Vygotsky LS. A formação Social da Mente. $4^{a}$ ed. São Paulo: Martins Fontes; 1994.

20. Peron SI, Guimarães LS, Souza LK. Amizade na adolescência e a entrada na universidade. Estud Pesqui Psicol. 2010;10(3):664-81.
21. Buendgens BB, Zampieri AMFM. A adolescente grávida na percepção dos médicos e enfermeiros da atenção básica. Esc Anna Nery Rev Enferm. 2012;16(1):64-72.

22. Gomes AP, Coelho UCD, Cavalheiro PO, Gonçalvez CAN, Rôças G, Batista RS. A Educação Médica entre mapas e âncoras: a aprendizagem significativa de David Ausubel, em busca da Arca Perdida. Rev Bras Educ Méd. 2008;32(1):105-11.

23. Mitre SM, Batista RS, Mendonça JMG, Pinto NMM, Meirelles CAB, Porto CP et al. Metodologias ativas de ensino-aprendizagem na formação profissional em saúde: debates atuais. Ciênc Saúde Coletiva. 2008;13(supl2):2133-44.

\section{Correspondência para:}

Liliane Parreira Tannús Gontijo e-mail: lilianetannus1@gmail.com

Av. João Naves de Ávila, 2121

Universidade Federal de Uberlândia

Campus Santa Mônica

38400-902 Uberlândia/MG 